\title{
LONG-TERM RESULTS OF CORE DECOMPRESSION FOR ISCHAEMIC NECROSIS OF THE FEMORAL HEAD
}

\author{
ADRIAN C. FAIRBANK, DEEPAK BHATIA, RIYAZ H. JINNAH. DAVID S. HUNGERFORD
}

From Johns Hopkins University School of Medicine, Baltimore, USA

We have studied the long-term results of core decompression as the sole treatment for Ficat stages $I$, II and III ischaemic necrosis of 128 femoral heads in 90 patients. The 5-, 10- and 15-year survival rates for the three stages were respectively: stage I $100 \%, 96 \%$ and $90 \%$; stage II $85 \%, 74 \%$ and $66 \%$; and stage III $58 \%$, $35 \%$ and $23 \%$. At a mean follow-up of 11 years $(4.5$ to 19), 55 hips had failed $(43 \%)$. No further surgery had been needed for $88 \%$ of stage-I, $72 \%$ of stage-II and $26 \%$ of stage-III hips; but despite the generally satisfactory clinical results, $56 \%$ of the hips had progressed radiographically by at least one Ficat stage. Complications of the core procedure included four fractures, all from postoperative falls, and one head perforation due to technical error.

We conclude that core decompression delays the need for total hip replacement in young patients with ischaemic necrosis.

J Bone Joint Surg [Br] 1994:76-B:42-9.

Received I8 January 1994: Accepted 7 March 1994

Ischaemic necrosis of the femoral head (INFH) is the underlying cause in $5 \%$ to $18 \%$ of hips requiring total replacement (THR) (Coventry et al 1974; Jacobs 1978). It is also a severely debilitating condition which may cause rapid, bilateral femoral head collapse in relatively young patients.

The natural history of INFH is uncertain, but in most cases there is early collapse of the head with loss of joint congruity leading to joint destruction. This has recently been reported to occur within four years of diagnosis in at

A. C. Fairbank, FRCS, Research Fellow in Adult Reconstructive Surgery

R. H. Jinnah, MD, Assistant Professor

Johns Hopkins Hospital and Medical School, 3449 Wilkens Avenue, Suite 305, Baltimore, Maryland 21229. USA.

D. Bhatia, FRCS, Orthopaedic Registrar

St George's Hospital. Blackshaw Road. London SW17 0QT. UK.

D. S. Hungerford. MD. Professor of Orthopaedic Surgery

Good Samaritan Hospital. Professional Office Building. G-1, 5601 Loch Raven Boulevard, Baltimore, Maryland 21239. USA.

Correspondence should be sent to Dr D. S. Hungerford.

(C1995 British Editorial Society of Bone and Joint Surgery 0301-620X/95/1839\$2.00 least $80 \%$ of cases (Ohzono et al 1992). Clinical failure of the hip is described in 68\% to 83\% of cases (Patterson 1964: Merle d'Aubigné et al 1965; Romer and Wettstein 1971). Collation of these reports shows clinical progression in $86 \%$ of hips at an average follow-up of 31 months. It has also been suggested that more than half the hips will undergo THR within three years (Aaron et al 1989; Stulberg et al 1991). Reported short-term results of the efficacy of core decompression vary greatly: Ficat (1985) found $89.5 \%$ success for precollapse INFH while Camp and Colwell (1986) had only 40\% success. We could find no documentation of the outcome at more than ten years. We have reviewed our experience of core decompression as the sole treatment for patients with INFH.

\section{PATIENTS AND METHODS}

The prospective study began in 1974 and includes 90 patients (45 men and 45 women), with 128 affected hips, who presented at the Good Samaritan Hospital, Baltimore, with pain in one or both hips. The diagnosis was established by either histology (123 hips) or radiography (5 hips). Core decompression was the sole surgical treatment for INFH between 1974 and 1980. All the patients were seen and examined by the senior author (DSH) and radiological staging was by the method of Ficat and Arlet (1980) (Table I) on anteroposterior and frog-lateral films.

Functional exploration was performed with Ficat pressure-recording needles, measuring the baseline resting pressure in the greater trochanter. A stress test was performed by injecting $5 \mathrm{ml}$ of saline through the trocar. Resting pressures above $30 \mathrm{mmHg}$ were regarded as abnormal and the stress test was considered abnormal if it caused a rise in pressure of $10 \mathrm{mmHg}$ or more sustained for over five minutes (Figs 1 and 2; Hungerford and Zizic 1978; Hunger-

Table I. Radiological staging of INFH (Ficat and Arlet 1980)

\begin{aligned} & \hline Stage \\ & \hline 0 Preclinical disease with no radiological signs \\ & I Preradiographic disease with no apparent radiological signs \\ & II Diffuse porosis, sclerosis or cysts \\ & III $\begin{array}{l}\text { Broken contour of the femoral head. or sequestrum present. } \\ \text { Normal joint space }\end{array} \\ &$ IV Flattened contour. Decreased joint space. Head collapse \\ & \hline\end{aligned}




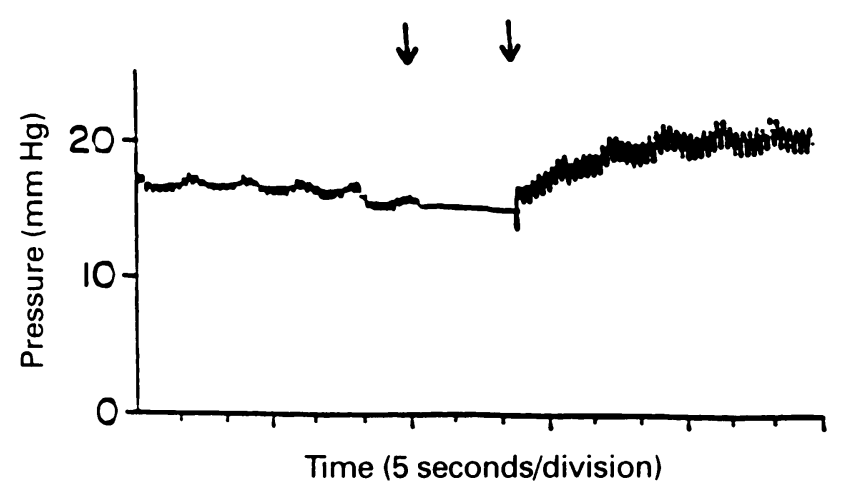

Fig. 1

Normal functional test for bone-marrow pressure and stress response. The arrows show the saline injection.

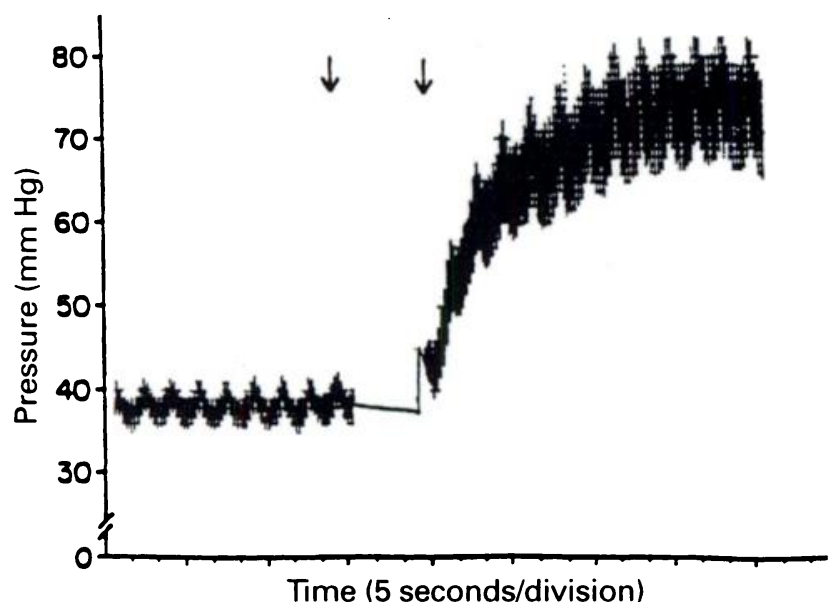

Fig. 2

An abnormal bone-marrow pressure and stress-test response in a patient with INFH.

ford 1979; Ficat 1985). Intraosseous venography was performed using 8 to $10 \mathrm{ml}$ of Renograffin 60, with radiographs at the end of injection and after five minutes. A positive test was recorded if the film revealed poor filling of the three main draining channels (liminocapsular, circumflex femoral, and gluteal vessels), diaphyseal reflux, and delayed clearance of contrast from the bone (Figs 3 and 4).

The indication for core decompression of a symptomatic hip was one or more of the following features; a predisposing risk factor; classical radiological features of INFH; a positive ${ }^{99 \mathrm{~m}} \mathrm{Tc}$ bone scan for INFH; a positive baseline and/ or stress test on functional exploration of the bone; and positive venography.

Core decompression. Core decompression was performed under general anaesthesia with the patient supine on a radiolucent table. An image intensifier was used to identify and locate precisely the entry point and the correct path for the coring device. The entry hole was placed just distal to the flare of vastus lateralis, in metaphyseal rather than diaphyseal bone. The precision of the entry point reduced the danger that it would be a significant stress riser (Fig. 5). The Ficat coring device was then introduced and a core of bone removed and sent for histological analysis. Postoperatively, patients remained partially weight-bearing on two crutches using a three-point gait for at least six weeks. Patients who had had bilateral simultaneous corings $(n=22)$ were instructed to adopt a four-point gait.

Histological examinations were made on decalcified specimens stained with haematoxylin and eosin. INFH was identified by the absence of osteocytes and the presence of dead osseous trabeculae. Histological examination by an independent pathologist confirmed the diagnosis in 123 of the 128 hips.

During the study period five other patients had core decompression; one who had normal histology and a subsequent normal clinical course was later found to have diabetic neuropathy. Four patients with previously undiagnosed tumours are the subject of a previous report (Meals, Hungerford and Stevens 1978). These five were excluded. The five patients not diagnosed histologically all had classic stage-III disease with early collapse and well-demarcated sequestrae. In these the coring was by bone drill because of the fear that the Ficat reamer would cause further damage to the femoral head.

Review. Patients were reviewed clinically and radiographically at 6 weeks, 3 and 6 months and annually thereafter. The long-term results were assessed from hospital records, serial radiographs, personal interviews and physical examination. The postoperative anteroposterior and frog-leg radiographs were reviewed by a blinded observer ( $\mathrm{RHJ}$ ) to assess progression. The five patients who had not been recently reviewed were assessed by telephone contact with the patients themselves, a relation, or private doctor, for information on clinical function and any subsequent operations. Contact was made with all patients; none was lost to follow-up.

Failure of the core procedure was recorded on the date when a further operation such as THR was required, or the modified Merle d'Aubigné score (Charnley 1979) for pain and function became less than 10. Statistical analysis was made by Kaplan-Meier survival analysis with assessment of $95 \%$ confidence intervals (Armitage 1971).

\section{RESULTS}

The average age of the patients at the time of the first core procedure was 40 years ( 15 to 85 ). Forty-five patients had bilateral INFH $(50 \%)$, and 38 of these were treated by bilateral core decompression, 22 by simultaneous coring. Seven of the bilaterally affected patients had one hip which was beyond stage III or had already had another surgical treatment. The underlying causes are listed in Table II, which shows that corticosteroid therapy was the most common association, with 53 patients $(59 \%)$ providing 78 of the cored hips $(61 \%)$. Eighteen of these patients had systemic lupus erythematosus; the other diagnoses are lis- 


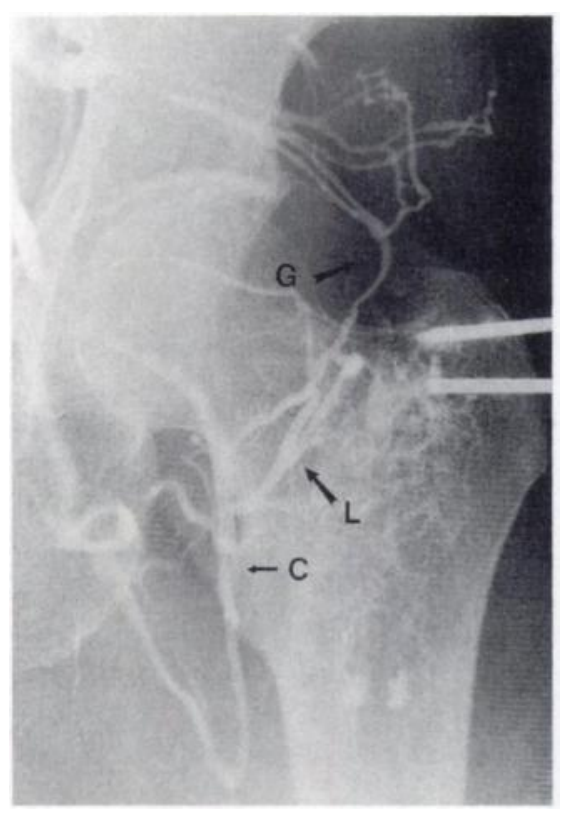

Fig. 3a

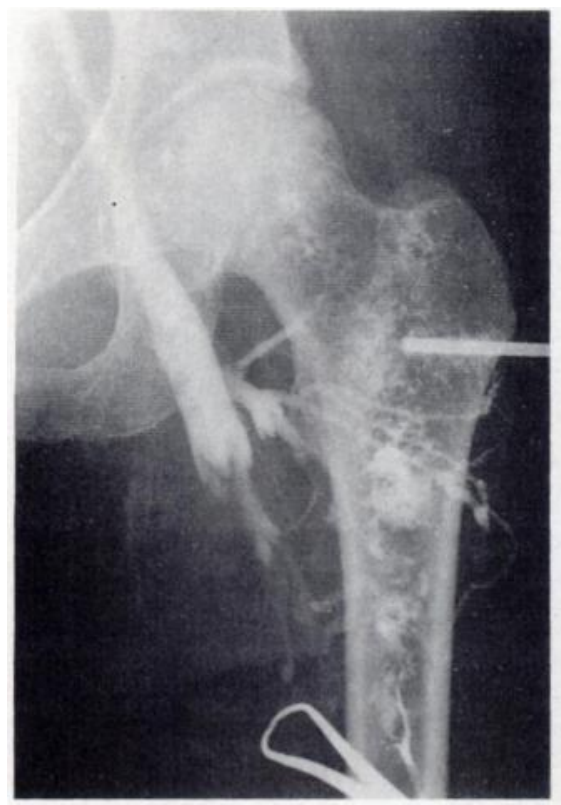

Fig. ta

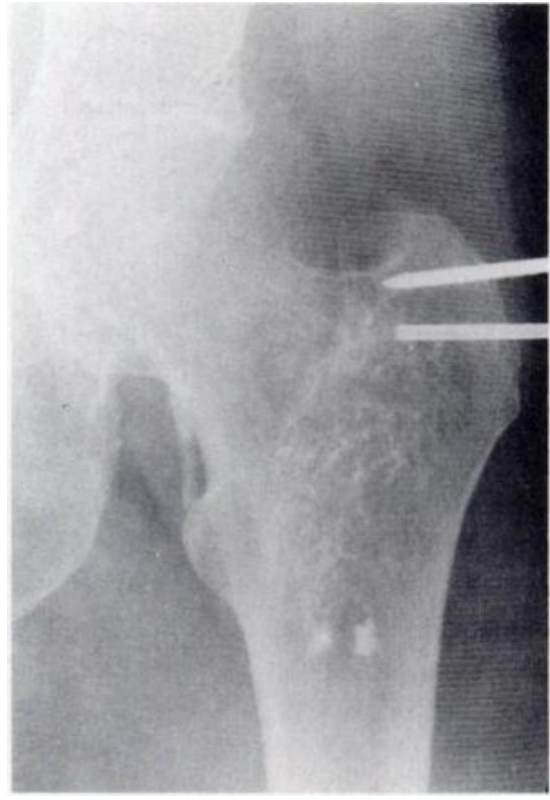

Fig. 3b

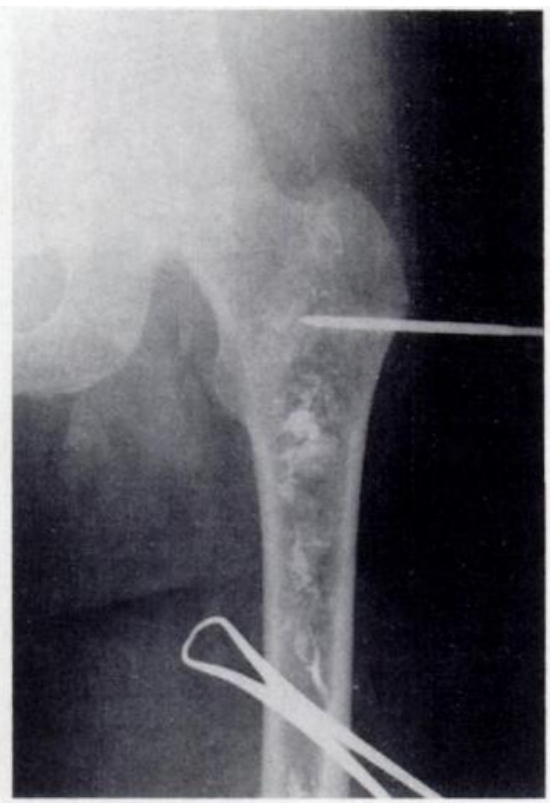

Fig. 4b
Normal intraosseous venography immediately after injection (a) and after five minutes (b). The groups of draining vessels are: L, liminocapsular: C, circumflex femoral: and $\mathrm{G}$, gluteal.

\begin{abstract}
Abnormal intraosseous venography immediately after injection (a) and after five minutes (b). The pressure and venography studies are performed in the intertrochanteric area. This indicates that haemodynamic abnormalities are detectable at some distance from the necrotic head.
\end{abstract}

ted in Table III. There were 25 hips at Ficat stage I, 51 at stage II, and 52 at stage III.

The results of functional exploration are shown in Table IV. Intraosseous pressure studies were performed on 122 of the 128 hips. Of these. 115 (94\%) showed either an elevated baseline or a positive stress test or both. Intraosseous venography was performed on 115 hips, and was positive in $106(92 \%)$. In three patients (5 hips) the study was not performed because of their known allergy to iodine.

Twenty-one of the 25 patients examined with precollapse disease (Ficat stage I) had both abnormal intraosseous pressures and abnormal venography, and all five stage-III hips with no histological confirmation had positive venographic and pressure studies.
By the final follow-up, ten patients had died. Eight of these were on steroids and died from their systemic disease; the other two had been murdered. Three of these ten patients had four hips converted to THR before they died. and their results are included. The other seven patients, (nine hips) had clinically satisfactory hips at the time of their death, at a mean of 90.1 months (25 to 168) after core decompression. The mean follow-up of those patients who did not progress to THR was 11 years (4.5 to 19).

The total failure rate for the study group was $43 \%$, that is 55 of the 128 hips cored had either been converted to THR or were deemed to require this on the basis of their hip score. In precollapse disease (stages I and II) 17 of 76 hips (22.4\%) had failed; for postcollapse disease, 38 of 52 hips 


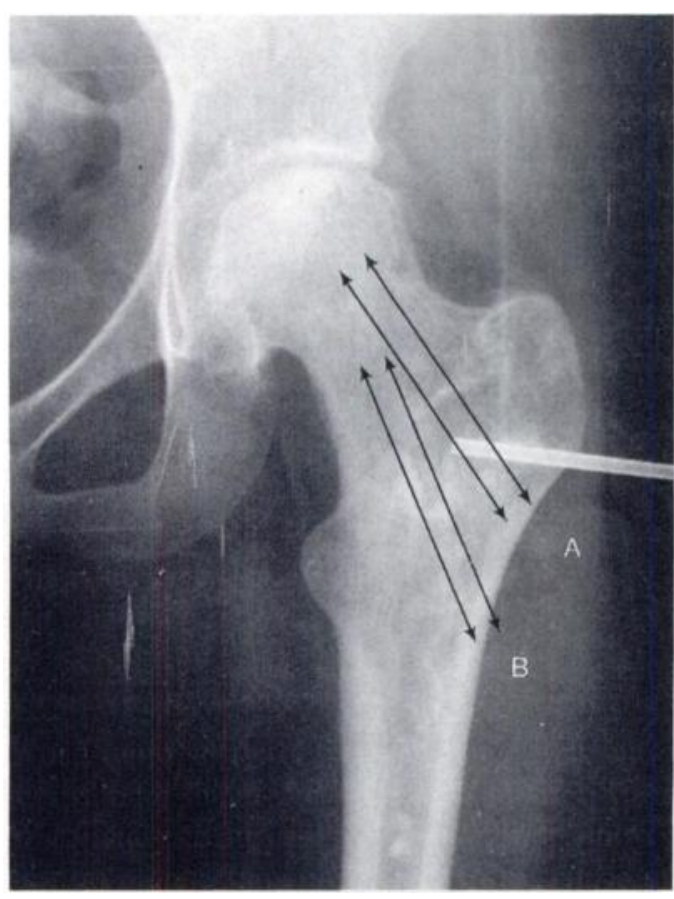

Fig. 5

To show the ideal placement for the pressure-recording trocar (in situ) and possible entry points for the coring device (parallel arrows). Line $A$ is recommended to avoid creating a significant stress riser in predominately cortical bone which would result from line $B$

(73\%) had failed (Table V). In the steroid-associated group, 35 of 53 hips $(66 \%)$ had THR after a mean delay of 4.6 years, but this high figure was because most of these hips already had stage-III changes at the time of core decompression. Patients who were on steroid treatment both before and after the core decompression had worse results than those who took steroids only before the procedure (Table VI).

Kaplan-Meier survival curves for all stages combined and for each individual stage are shown in Figures 6 and 7 , together with $95 \%$ confidence limits at the maximum follow-up which allowed this calculation. There was $96 \%$ survival $(95 \% \mathrm{Cl} \pm 7.4)$ at 12 years for Ficat stage I, $83 \%$ survival $(95 \% \mathrm{CI} \pm 10.03)$ at seven years for stage II, and $60 \%(95 \% \mathrm{CI} \pm 13.13)$ at two years for stage III. The small number of survivors at later time periods make the survival figures unreliable at the $95 \%$ level. Radiological progression, defined as an increase in the Ficat stage for the involved hip, was seen in 41 of 73 hips (56\%). Again, this was related to the stage of the disease: $22 \%$ of stage I $(5 / 22), 62 \%$ of stage II (23/37) and $93 \%$ of stage III (13/14) had progressed by at least one Ficat stage at final followup.

The complications are listed in Table VII. All four fractures of the proximal femur occurred after trauma, such as a fall from crutches on to the operated hip. There were no spontaneous fractures. One fracture was undisplaced and required only bed-rest followed by a hip spica; the other
Table II. Conditions and treatment predisposing to INFH in 90) patients

\begin{tabular}{lll}
\hline & $\begin{array}{l}\text { Number of } \\
\text { patients }\end{array}$ & $\begin{array}{l}\text { Number } \\
\text { of hips }\end{array}$ \\
\hline Corticosteroids & 53 & 78 \\
Alcohol & 19 & 27 \\
Idiopathic & 9 & 12 \\
Sickle-cell disease & 2 & 4 \\
Dislocation & 3 & 3 \\
Legg-Calvé-Perthes disease & 2 & 2 \\
Gaucher`s disease & 1 & 1 \\
Slipped upper femoral epiphysis & 1 & 1 \\
\hline
\end{tabular}

Table III. Reasons for steroid therapy in 53 patients with INFH

\begin{tabular}{ll}
\hline & Number \\
\hline Systemic lupus erythematosus & 18 \\
Chronic renal failure & 8 \\
Rheumatoid disease & 6 \\
Asthma or other respiratory disease & 5 \\
Chronic hepatitis & 4 \\
Bell's palsy & 2 \\
Giant-cell arteritis & 2 \\
Polyarteritis & 2 \\
Haemolytic anaemia & 1 \\
Systemic sclerosis & 1 \\
Chronic leukaemia & 1 \\
Juvenile arthritis & 1 \\
Polymyalgia rheumatica & 1 \\
Psoriasis & 1 \\
\hline
\end{tabular}

three required open reduction and internal fixation. All four patients had precollapse disease, and none progressed. The one case of head perforation was early in the series in a patient with stage-III disease and resulted from the technical error of failing to clear the coring device of impacted bone. This patient remained partially weight-bearing for ten weeks, but THR was required 35 months later for collapse of the head. One of the two patients with deep venous thrombosis had a non-fatal pulmonary embolus.

\section{DISCUSSION}

A variety of treatments has been used for early INFH and there is considerable controversy about its management. It 


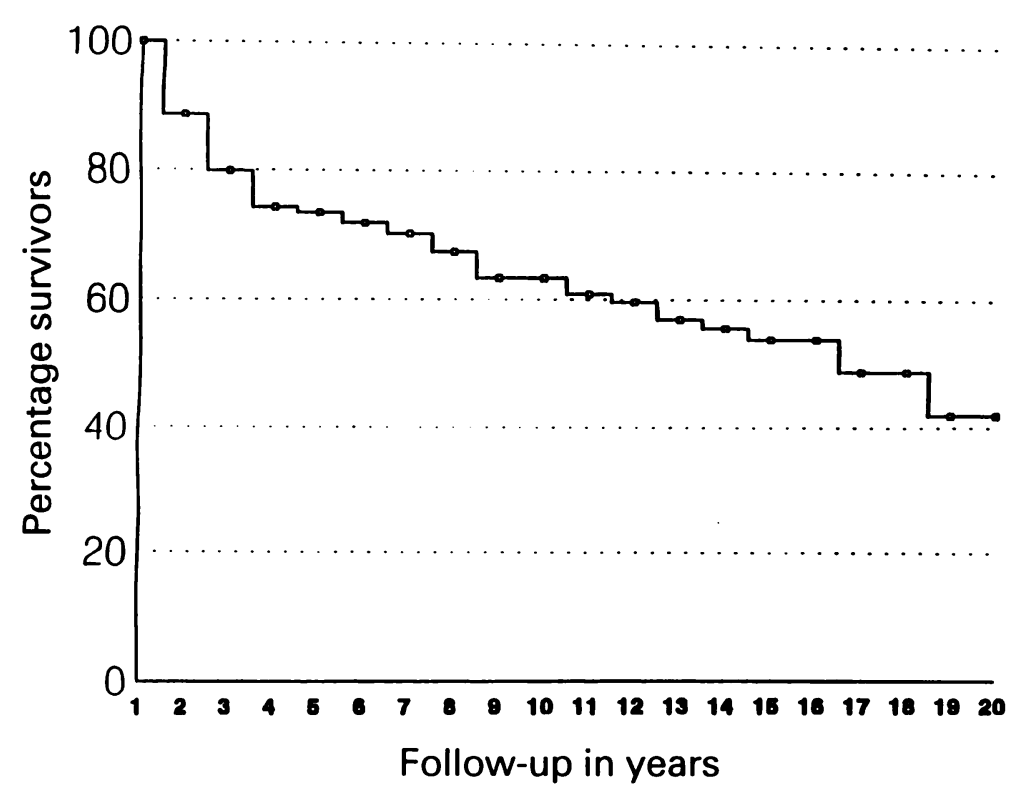

\begin{tabular}{cccc}
\multicolumn{4}{l}{ All Ficat Stages } \\
\cline { 2 - 4 } Years & Died & Withdrawn & Surviving \\
\hline 0 & - & - & 129 \\
1 & 15 & - & 129 \\
2 & 11 & 3 & 114 \\
3 & 7 & - & 100 \\
4 & 1 & - & 93 \\
5 & 2 & 4 & 92 \\
6 & 2 & 5 & 86 \\
7 & 3 & 6 & 79 \\
8 & 4 & 6 & 60 \\
9 & - & 7 & 53 \\
10 & 2 & 2 & 49 \\
11 & 1 & 3 & 40 \\
12 & 2 & 3 & 34 \\
13 & 1 & 5 & 30 \\
14 & 1 & 3 & 14 \\
15 & - & 5 & 2 \\
16 & 2 & 9 & 2 \\
17 & - & 2 & \\
18 & 1 & 9 & 2 \\
19 & - & 2 & - \\
20 & - & - & \\
\hline
\end{tabular}

Fig. 6

Survival curve for all 129 hips with numbers for each year of follow-up.

Table IV. Results of the functional exploration of bone in 128 hips, related to the radiological stage of INFH, by number and percentage

\begin{tabular}{llllllllll}
\hline & \multicolumn{3}{l}{ Intraosseous pressure } & & \multicolumn{5}{l}{ Intraosseous venography } \\
\cline { 2 - 3 } Ficat stage & Total & Not done & Normal & Abnormal & & Total & Not done & Normal & Abnormal \\
\hline I & 25 & 2 & 0 & $23(100)$ & 25 & 4 & 0 & $21(100)$ \\
II & 51 & 2 & 4 & $45(92)$ & 51 & 2 & 5 & $4(89)$ \\
III & 52 & 2 & 3 & $47(94)$ & 52 & 7 & 4 & $41(91)$ \\
\hline
\end{tabular}

usually affects young patients, who present with a painful hip. The natural history is progression to femoral head collapse requiring THR in most cases. Untreated disease has been reported to progress to the need for arthroplasty in 76\% (Musso et al 1986), 81.5\% (Stulberg et al 1991), and $100 \%$ of cases (Tooke et al 1988). INFH is often bilateral, and in many cases is associated with a severe disabling systemic disease such as systemic lupus erythematosus. The long-term results of THR in these patients are known to be worse than those in matched patients with other hip diseases (Dorr, Takei and Conaty 1983; Cornell, Salvati and Pellicci 1985; Katz et al 1991). No medical treatment has been successful and therefore many surgical procedures have been advocated for the precollapse stage (Meyers 1978; Smith, Bonfiglio and Montgomery 1980; Sugioka, Katsuki and Hotokebuchi 1982; Steinberg et al 1984; Ficat 1985).

Core decompression has several potential advantages. It is within the surgical abilities of orthopaedic surgeons who have experience of the three-dimensional appearance of the femoral neck provided by the image intensifier. In addition, it is reproducible and well tolerated by the patients, who can return to normal activity after six weeks.
Table V. Failure of core decompression at a mean follow-up of 11 years, related to radiological stage

\begin{tabular}{llll}
\hline & Failure & & $\begin{array}{l}\text { Mean delay } \\
\text { before failure } \\
\text { (yr; range in } \mathbf{m t h})\end{array}$ \\
\cline { 2 - 4 } & Number & Per cent & 9.75 (48 to 213) \\
\hline I & 3 of 25 & 12 & $4.75(8$ to 194) \\
II & 14 of 51 & 28 & $3.3(3$ to 190) \\
\hline
\end{tabular}

We have shown a low complication rate although Camp and Colwell (1986) reported a 10\% incidence of postoperative proximal femoral fracture in 40 cored hips and Hopson and Siverhus (1988) reported one fracture in 17 patients. Careful placement of the entry point reduces this risk; in Camp and Colwell's (1986) series of 40 patients having core decompression by 13 different surgeons the entry point was $4 \mathrm{~cm}$ below the trochanteric ridge through fully constituted lateral cortex (Fig. 5), producing a more significant stress riser. We warn our patients to continue protected weight-bearing on every step for six weeks, and our total complication rate was only $4 \%$ in 128 core 


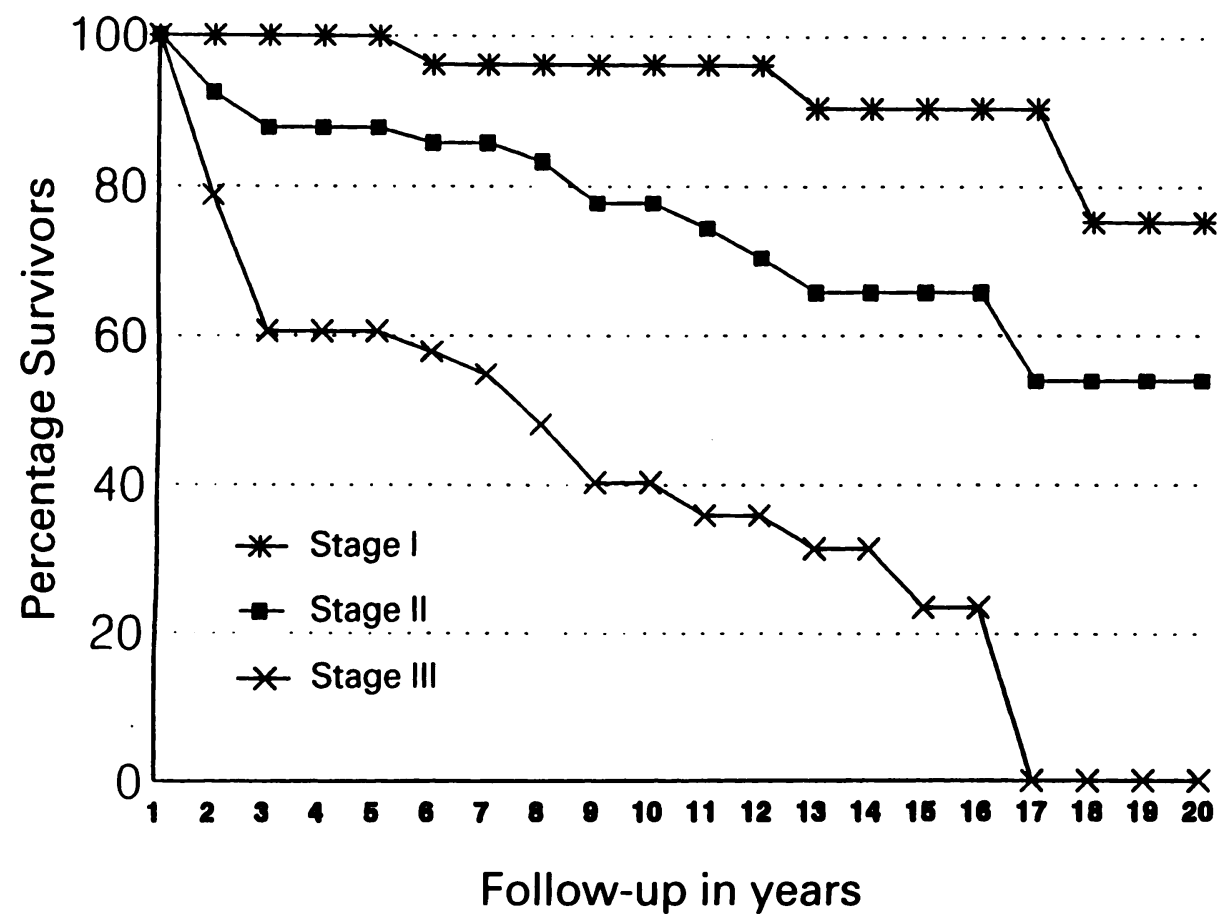

Fig. 7

Survival curves for each Ficat stage with numbers for each year of follow-up.

\begin{tabular}{|c|c|c|c|c|c|c|c|c|c|}
\hline \multirow[b]{2}{*}{ Years } & \multicolumn{3}{|c|}{ Stage I } & \multicolumn{3}{|c|}{ Stage II } & \multicolumn{3}{|c|}{ Stage III } \\
\hline & Died & Withdrawn & Surviving & Died & Withdrawn & Surviving & $\overline{\text { Died }}$ & Withdrawn & Surviving \\
\hline 0 & - & - & 26 & - & - & 51 & - & - & 52 \\
\hline 1 & - & - & 26 & 4 & - & 51 & 11 & - & 52 \\
\hline 2 & - & - & 26 & 2 & 1 & 47 & 9 & 2 & 41 \\
\hline 3 & - & - & 26 & - & - & 47 & 7 & - & 30 \\
\hline 4 & - & - & 26 & - & - & 47 & 1 & - & 23 \\
\hline 5 & - & 1 & 26 & 1 & 1 & 44 & $i$ & 2 & 22 \\
\hline 6 & 1 & - & 25 & - & 4 & 42 & 1 & 1 & 19 \\
\hline 7 & - & - & 25 & 1 & 5 & 38 & 2 & 1 & 17 \\
\hline 8 & - & - & 25 & 2 & 3 & 32 & 2 & 3 & 14 \\
\hline 9 & - & 3 & 24 & - & 4 & 27 & - & - & 9 \\
\hline 10 & - & - & 24 & 1 & 2 & 23 & 1 & - & 9 \\
\hline 11 & - & - & 24 & 1 & 3 & 20 & - & - & 8 \\
\hline 12 & - & 1 & 21 & 1 & 2 & 16 & 1 & - & 8 \\
\hline 13 & 1 & 1 & 20 & - & 1 & 13 & - & 3 & 7 \\
\hline 14 & - & 1 & 18 & - & 2 & 12 & 1 & - & 4 \\
\hline 15 & - & 1 & 17 & - & 1 & 10 & - & 2 & 3 \\
\hline 16 & - & 4 & 16 & 1 & 5 & 8 & 1 & - & 1 \\
\hline 17 & - & 2 & 12 & - & - & 8 & - & - & 0 \\
\hline 18 & 1 & 8 & 10 & - & 1 & 2 & - & - & - \\
\hline 19 & - & 1 & 1 & - & 1 & 1 & - & - & - \\
\hline 20) & - & - & 0 & - & - & 0 & - & - & - \\
\hline
\end{tabular}

procedures. Even this can be reduced by exact technique: Steinberg et al (1984) had no fracture complications in over 300 cored hips. With increased experience, we have had no fractures in over 150 core decompressions performed since 1980.
The efficacy of core decompression has been questioned (Camp and Colwell 1986; Hopson and Siverhus 1988) since a failure rate of $60 \%$ has been reported, but even $40 \%$ success is better than the natural history. In our series, hips in Ficat stages I and II showed a survivorship of $82.5 \%$ at 
Table VI. Effect of steroid therapy on survival for each radiological stage, by number and percentage

\begin{tabular}{lcc}
\hline Ficat stage & $\begin{array}{l}\text { Steroids before } \\
\text { and after coring }\end{array}$ & $\begin{array}{l}\text { Steroids only } \\
\text { before coring }\end{array}$ \\
\hline I & 2 of $7(29)$ & 1 of $9(I I)$ \\
II & 5 of $15(33)$ & 5 of $17(29)$ \\
III & 18 of $24(75)$ & 4 of $6(67)$ \\
\hline
\end{tabular}

Table VII. Complications in 128 coring procedures by number and percentage

\begin{tabular}{ll}
\hline Fracture related to core track & $4(3.1)$ \\
Perforation of femoral head & $1(0.8)$ \\
Deep venous thrombosis & $2(1.6)$ \\
Retained drain & $1(0.8)$ \\
\hline
\end{tabular}

ten years. Our radiographic progression, however, was worse than that reported by Ficat (1985), who found 14\% progression for stage I and 34\% for stage II. Our results are similar to the $16 \%, 58 \%$ and $90 \%$ for stages I, II and III respectively reported by Warner et al (1987), and these higher figures may reflect the high proportion of patients with steroid-associated INFH. Tooke et al (1988) also found a higher failure rate in patients with steroid-associated INFH who continued steroid therapy after the coring procedure. Steroid therapy after coring should therefore be minimised as far as possible in the context of the underlying disease.

There have been two prospective studies of core decompression for INFH. Stulberg et al (1991) reported 55 hips in 36 patients with randomisation into two groups, 29 hips treated by core decompression and 26 hips treated conservatively. As judged by the Harris hip score, $70 \%$ of surgically treated patients with stage-I disease had successful results as against only $20 \%$ of conservatively treated hips. In stage-II disease, $71 \%$ of surgically treated hips were satisfactory as against none of 7 without operation. For stage-III disease, $73 \%$ of core decompression hips had a successful result, as compared with only $10 \%$ of nonsurgically treated hips.

Robinson and Springer (1992) studied asymptomatic, MRI-detected lesions, and compared core decompression with protected weight-bearing alone. They reported clinical success in 15 of 19 hips $(79 \%)$ in the core decompression group, with only 16 of 19 hips (84\%) needing THR.

Most of the patients affected with this condition are young, and this is an important factor. Our series of patients had an average age of 40 years and there was a $50 \%$ requirement for core decompression for bilateral disease. Total joint replacement gives poor results in a young population (Chandler et al 1981; Dorr et al 1983) and it seems probable that our group of patients would have been seriously debilitated by untreated INFH which would require THR.

The long-term survival of hips in Ficat stages I and II INFH after core decompression provides significant palliation and delays the need for further surgical treatment, sometimes for long periods. Total hip replacement is likely to improve with time, and therefore the delay in replacement in this group of young patients may also result in improvement in the results of arthroplasty. On the basis of our long-term results we would advocate the use of core decompression for precollapse stages of INFH. We also advise its use after minimal collapse in patients who fully understand the importance of delaying THR and who can be relied on to modify their activity level.

No benefits in any form have been received or will be received from a commercial party related directly or indirectly to the subject of this article.

\section{REFERENCES}

Aaron RK, Lennox D, Bunce GE, Ebert T. The conservative treatment of osteonecrosis of the femoral head: a comparison of core decompression and pulsing electromagnetic fields. Clin Orthop 1989; 249:209-18.

Armitage P. Statistical methods in medical research. Oxford, etc: Blackwell Scientific, 1971.

Camp JF, Colwell CW Jr. Core decrompression of the femoral head for osteonecrosis. J Bone Joint Surg /Am/ 1986:68-A:1313-9.

Chandler HP, Resnick FT, Wixson RL, McCarthy JC. Total hip replacement in patients younger than 30 years old: a five-year followup study. J Bone Joint Surg [Am] 1981:63-A:1426-34.

Charnley J. Low friction arthroplasty of the hip: theory and practice. Berlin, etc: Springer-Verlag. 1979:2()-90.

Cornell CN, Salvati EA, Pellicci PM. Long-term follow-up of total hip replacement in patients with osteonecrosis. Orthop Clin North Am 1985:16:757-69.

Coventry MB, Beckenbaugh RD, Nolan DR, Ilstrup DM. 2.012 total hip arthroplasties: a study of postoperative course and early complications. J Bone Joint Surg (Am) 1974:56-A:273-84.

Dorr LD, Takei GK, Conaty JP. Total hip arthroplasties in patients less than forty-five years old. J Bone Joint Surg /Am/ 1983:65-A:474-9.

Ficat RP. Idiopathic bone necrosis of the femoral head: early diagnosis and treatment. J Bone Joint Surg /Br/ 1985;67-B:3-9.

Hopson CN, Siverhus SW. Ischemic necrosis of the femoral head: treatment by core decompression. J Bone Joint Surg [Am] 1988;70-A:1048-51.

Hungerford DS. Bone marrow pressure, venography and core decompression in ischemic necrosis of the femoral head. In: The hip: proceedings of the seventh open scientific meeting of The Hip Society: St Louis: CV Mosby, 1979:218-37.

Hungerford DS, Zizic TM. Alcoholism associated ischemic necrosis of the femoral head: early diagnosis and treatment. Clin Orthop 1978:130:144-53.

Jacobs B. Epidemiology of traumatic and nontraumatic osteonecrosis. Clin Orthop 1978:130:51-67.

Katz RL, Bourne RB, Rorabeck CH, McGee H. Total hip arthroplasty in patients with avascular necrosis of the hip: follow-up observations on cementless and cemented operations. Clin Orthop 1991;281:145-51.

Meals RA, Hungerford DS, Stevens MB. Malignant disease mimicking arthritis of the hip. JAMA 1978:239:1070-1.

Merle d'Aubigné R, Postel M, Mazabraud A, Massias P, Gueguen J. Idiopathic necrosis of the femoral head in adults. $J$ Bome Joint Surg [Br] 1965:47-B:612-33.

Meyers MH. The treatment of osteonecrosis of the hip with fresh osteochondral allografts and with the muscle pedicle graft technique Clin Orthop 1978;130:202-9. 
Musso ES, Mitchell SN, Schink-Ascani M, Bassett CAL. Results of conservative management of osteonecrosis of the femoral head: a retrospective review. Clin Orthop 1986;207:209-15.

Ohzono K, Saito M, Sugano N, Takaoka K, Ono K. The fate of nontraumatic avascular necrosis of the femoral head: a radiologic classification to formulate progress. Clin Orthop 1992:277:73-8.

Patterson RJ, Bickel WH, Dahlin DC. Idiopathic avascular necrosis of the head of the femur: a study of fifty-two cases. $J$ Bone Joint Surg [Am/ 1964:46-A:267-82.

Robinson HJ Jr, Springer JA. Success of core decompression in the management of early stages of avascular necrosis: a four-year prospective study. Orthop Trans 1992-1993:16:707.

Romer U, Wettstein P. Results of 81 Swiss patients with IINFH. In: Zinn WM. ed. Idiopathic ischemic necrosis of the femoral head in adults. Thieme, Stuttgart, 1971:205-12.

Smith KR, Bonfiglio M, Montgomery WJ. Non-traumatic necrosis of the femoral head treated with tibial bone grafting: a follow-up note. J Bone Joint Surg /Am] 1980;62-A:845-7.
Steinberg ME, Brighton CT, Steinberg DR, Tooze SE, Hayken GD. Treatment of avascular necrosis of the femoral head by a combination of bone grafting, decompression, and electrical stimulation. Clin Orthop 1984;186:137-53.

Stulberg BN, Davis AW, Bauer TW, Levine M, Easley K. Osteonecrosis of the femoral head: a prospective randomized treatment protocol. Clin Orthop 1991;268:140-51.

Sugioka Y, Katsuki I, Hotokebuchi T. Transtrochanteric rotational osteotomy of the femoral head for the treatment of osteonecrosis: follow-up statistics. Clin Orthop 1982:169:115-26.

Tooke SMT, Nugent PJ, Bassett LW, et al. Results of core decompression for femoral head osteonecrosis. Clin Orthop 1988;228:99-104.

Warner JJ, Philip JH, Brodsky GL, Thornhill TS. Studies of nonraumatic osteonecrosis: the role of core decompression in the treatment of nontraumatic osteonecrosis of the femoral head. Clin Orthop 1987;225:104-27. 